\title{
NOVA POSSIBILIDADE CIRÚRGICA NA TERAPÊUTICA DAS FISTULAS LIQUÓRICAS
}

\author{
NeLson Pires FerReira *
}

As fístulas liquóricas espontâneas ou traumáticas freqüentemente representam situações de difícil controle. A sua persistência acarreta, não raramente, meningite, cerebrite e abscesso contíguos à solução de continuidade dural. Esse problema vem sendo estudado desde o século passado sem uma solução definitiva. A extensa revisão feita por Dickman ${ }^{2}$ em 1971 dá uma idéia global do problema.

Insucessos na localização do trajeto fistuloso em pacientes com rinorréia, fizeram com que nos detivéssemos sobre o assunto e idealizassemos uma nova derivação fechada, sem risco de contaminação e que absorvesse líquido cefalorraqueano por tempo limitado.

\section{MATERIAL E MÊTODO}

Nos últimos 5 pacientes com fístula liquórica pós-traumática e espontânea em que a fístula não foi controlada com administração de soluções hipertônicas e de Diamox e mediante punçōes lombares repetidas, foram realizadas derivações liquóricas do espaço subaracnóideo lombar para a musculatura paravertebral no mesmo nivel.

Técnica cirúrgica - Incisão mediana da pele na região lombar, deslocamento unilateral da fáscia e da musculatura paravertebral, junto às apófises espinhosas; abordagem igual à usada para retirada de disco intervertebral. Afastamento da musculatura paravertebral e abordagem do canal espinal mediante remoção de pequena porção das lâminas de L4-L5. Após a excisão do ligamento amarelo é alcançađo o espaço epidural e a dura-mater do fundo de saco. Dois fios de sutura são passados através da dura-mater separados em 3-4 mm, sendo feito pequeno pertuito na duramater e aracnóide, o suficiente para ser introduzido o cateter ventricular da válvula de Pudenz (Fig. 1). Uma porção do cateter, com $6 \mathrm{~cm}$ de comprimento, é utilizada; um centímetro é colocado no espaço subaracnóideo sendo o restante, com diversos orificios, colocado entre as lâminas posteriores de L2-L3-L4 e a musculatura paravertebral já desinserida para a abordagem do canal. O cateter é fixado com os fios previamente passados, usando a técnica de fixaçāo de dreno de torax (Fig. 2). Esta manobra evita o deslocamento do tubo de drenagem. O líquido cefalorraqueano passa a sair do espaço subaracnóideo lombar para a cavidade artificialmente criada, limitada pelas lâminas posteriores e pela musculatura paravertebral, sendo absorvido por esta. Não temos dados exatos do tempo de absorção liquórica a este nível. Parece ser em torno de duas semanas, período em que os pacientes deixam de se queixar de cefaléia decorrente da hipotensão liquórica.

Trabalho realizado no Instituto de Neurocirurgia de Porto Alegre: * Professor Assistente do Departamento de Cirurgia da UFRGS e membro do Instituto de Neurocirurgia. 


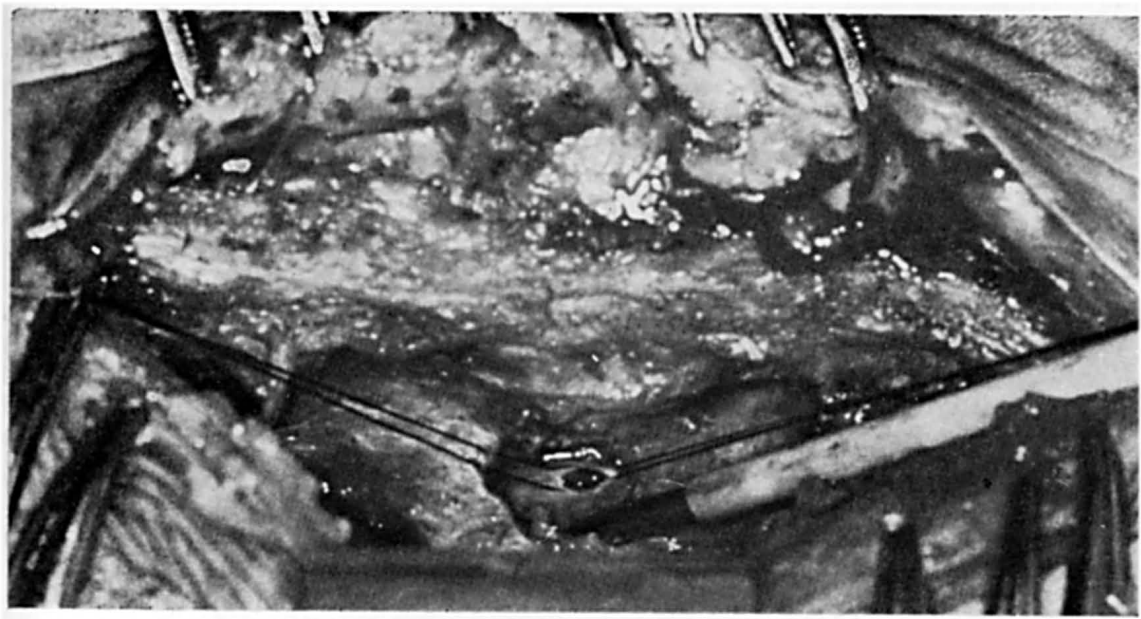

Fig. 1 - Aspecto do ato cirúrgico onde é possível observar o descolamento da musculatura paravertebral, a abordagem do canal mediante pequena remoção óssea das lâminas, os fios de fixação do cateter passados na dura-mater $e$ o pertuito realizado nesta e na aracnóide para a introdução do cateter.

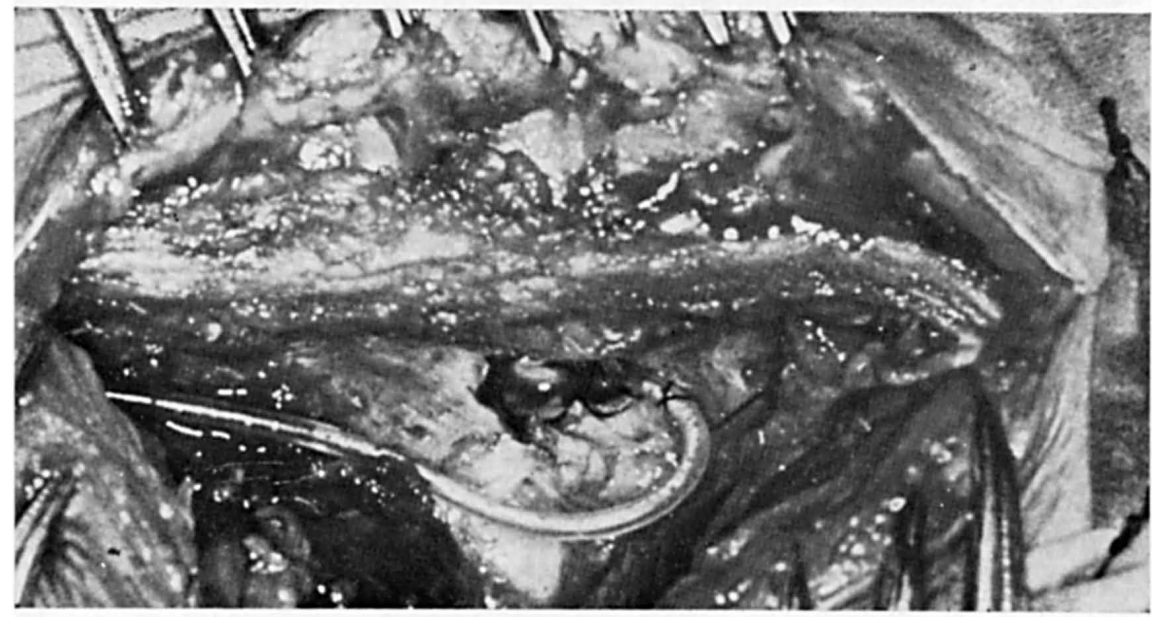

Fig. 2 - Aspecto do ato cirúrgico mostrando o cateter já introduzido no espaço subaracnóideo lombar e fixado pelos fios de suturas. Posição definitiva. 


\section{A S U I S T C A}

Caso 1 - A.M., 23 anos, sexo feminino, branca, internada em 15-5-1971 (Reg. n.o 9016/71). Há dois meses a paciente foi atingida por projétil de revólver que penetrou na região zigomática esquerđa, ficando inconsciente durante quatro dias. Notou, desde então, queda da pálpebra direita e perda abundante de liquido pelas fossas nasais. Exame clinico-neurológico - Paralisia completa do III e IV nervos cranianos à direita, saída de líquido cefalorraqueano (LCR) pelas narinas. Radiografias do crânio: fragmentos do projétil nos ossos da face à esquerda e na cavidade craniana com localização parasselar à direita. Cirurgia - Foi feita derivação liquórica do espaço subaracnóideo lombar para a musculatura paravertebral, com desaparecimento da drenagem liquórica pelas narinas 3 dias após a intervenção cirúrgica. A paciente permaneceu em decúbito elevado por uma semana. Revisão neurológica, feita 20 meses após, mostrava cura da fístula, havendo persistência da oftalmoplegia.

Caso 2 - C.A.C., 16 anos, sexo masculino, branco, internado em 25-11-1971 (Reg. n.o 83.654). No pós-operatório de cirurgia para correção de septo nasal o paciente passou a apresentar, quando baixava a cabeça, saída de líquido pelas narinas por rotura cirúrgica da lâmina crivosa do etmoide durante cirurgia septal. Foi tratado durante 15 dias com solução de Manitol $2 \mathrm{~g} / \mathrm{kg} / \mathrm{dia}$, punções lombares repetidas e antibióticoterapia, não havendo controle da fístula. Após a realização da derivação liquórica do espaço subaracnóideo lombar para a musculatura paravertebral houve diminuição progressiva da saída de LCR, com seu desaparecimento no quinto dia de pós-operatório. O paciente permaneceu em decúbito elevado por uma semana. Seis meses após a realização da derivação lombar o paciente passou a referir dor irradiada ao longo da face posterior do membro inferior esquerdo que o impossibilitava de jogar futebol. Nessa data foi removido o cateter com desaparecimento da queixa. Avaliação realizada 18 meses após a primeira intervenção cirúrgica mostrava controle da fístula.

Caso 3 - E.C., 3 anos, sexo feminino, branca, internada em 30-1-1972 (Reg. n.o 9964/72). No data da internação a paciente sofrera traumatismo cranioencefálico por queda. Exame clínico-neurológico — Obnubilação, sinal de Babirky bilateral, otorréia à esquerda. Foi tratada com solução de Manitol $2 \mathrm{~g} / \mathrm{kg} /$ dia, punções lombares diárias e antibióticoterapia. No quinto dia foi identificada meningite, havenđo persistência da fístula. No sétimo dia de internação foi realizada derivação liquórica lombar para a musculatura paravertebral. Um mês após teve alta hospitalar curada da meningite e da fístula liquórica. Não foi possivel obter reavaliação ulterior.

Caso 4 - J.E.P., 47 anos, sexo masculino, branco, internado em 13-9-1972 (Reg. n. ${ }^{\circ}$ 10.781/72). Na data da internação o paciente sofrera traumatismo cranioencefálico. Exame clinico-neurológico - Coma vigil, anisocoria com diâmetro pupilar maior à direita, hemiparesia motora à esquerda, otorragia e otorréia à direita. Radiografias de crânio: fratura parieto-temporal com irradiação para a base, à cireita. Angiografia carotidea direita: hematoma extradural parieto-temporal que foi removido mediante craniotomia com trefina. Três dias após a remoção do hematoma persistia a fistula com drenagem de grande volume de LCR. Nessa data foi realizada derivação liquórica lombar para a musculatura paravertebral com cura da fístula. O paciente veio a falecer dias após por processo pneumônico devido a pseudomonas.

CASO 5 - M.M.M., 45 anos, sexo feminino, branca, internada em 3-9-1973 (Reg. n.o 11.897/73). Desde o mês de janeiro de 1973 a paciente apresenta saida abundante de liquido claro pelas fossas nasais, aumentando o fluxo quando inclina a cabeça para a frente. Há aproximadamente um ano fato semelhante ocorrera com curta duração; há três anos sofrera traumatismo cranioencefálico sem perda de consciência. A paciente apresenta hipertensão arterial, tendo sido várias vezes operada (nefrectomia, herniorrafia, colecistectomia, apendicectomia e amputação do primeiro dedo da mão esquerda). Exame neurológico normal. Quando inclina a cabeça para a frente ou quando abaixa-se é possivel observar saída, pelas fossas nasais, 
de abundante quantidade de líquido claro que modifica a cor da glicofita. Radiografias de crânio normais. Cintilografia cisternal mostrou saída de grande quantidade de material radioativo pelas narinas. Cirurgia - Derivacão liquórica do fundo de saco dural lombar para a musculatura paravertebral. No terceiro dia de pós-operatório cessou a drenagem liquórica pelas narinas. A paciente foi mantida em posição semisentada por duas semanas. Revisão feita em fins de novembro, três meses após a intervenção, mostrava controle da fístula.

\section{COMENTARTOS}

A presença de fístula liquórica é potencialmente perigosa, em nossa experiência, face a grande incidência de complicações infecciosas relacionadas com o parênquima nervoso e suas coberturas meníngeas. A tentativa de cura por meios clínicos como repouso em decúbito elevado, administração de soluções hipertônicas e de Diamox e a prática de punções lombares repetidas com o intuito de diminuir a pressão liquórica e com isto dar tempo para uma cicatrização dural satisfatória, é válida. Infelizmente todas essas medidas, mesmo associadas e com proteção antibiótica, nem sempre controlam a fístula ou evitam a infecção. Nesses casos é necessário tomar medidas mais radicais para evitar complicações graves e mesmo a morte desses pacientes.

Diversas soluções tem sido propostas: a tentativa de localização do pertuito fistuloso com correção do mesmo mediante novas suturas, quando situado no escalpe, a anteposição de fáscia, dura-mater, músculo, acrilico ou cera quando a fístula se localiza na cavidade craniana 1, 2,5,6. Entre os meios indiretos, que visam a diminuir a pressão do LCR na zona de fragilidade dural, tem sido propostas as derivações liquóricas à distância do trajeto fistuloso, como drenagens liquóricas em aparelhos fechados com ou sem controle da pressão de drenagem e, mais recentemente, derivações valvuladas para a circulação ou para o peritôneo ${ }^{4}$.

As fístulas liquóricas se mantém devido o gradiente de pressão entre a cavidade craniana e o exterior, não havendo oportunidade de cicatrização adequada das coberturas encefálicas, mais especialmente a cicatrização dural. Nas drenagens extracranianas, além da dificuldade do controle do fluxo liquórico porque os aparelhos propostos são relativamente complexos e de difícil manejo, há o risco da contaminação atravẻs da agulha ou do cateter.

Nas derivações valvulares, devido a um gradiente de pressão que é controlado pela característica da válvula utilizada, nem sempre é conseguida a hipotensão suficiente para permitir a cicatrização dural. Esse fato foi observado pelo autor no caso 5 , já registrado em publicação anterior ${ }^{3}$. Nessa comunicação era proposta a derivação ventrículo-espaço subcutâneo do pescoço com a mesma finalidade. Apesar de haver controle da fístula em todos casos observamos que, em alguns deles, houve necessidade de reintervenção para desobstrução da extremidade ventricular do cateter. Esse fato fez com que pensassemos em uma solução na qual o cérebro não interviesse como causa de insucesso, motivando obstrução. Partimos, então, para a derivação lombar na qual seria afastada esse óbice. O liquido cefalorraqueano drenaria do extenso espaço subaracnóideo lombar, sem interferência da massa encefálica e/ou do plexo coróideo como ocorre nos ventriculos laterais. A mus- 
culatura paravertebral teria, na absorção do LCR, o mesmo papel que o espaço subcutâneo do pescoço. Além dessas possíveis vantagens, um gradiente de pressão maior entre o orifício da fístula e o fundo de saco dural, condiciona uma pressão praticamente de zero ao nível do pertuito se o paciente for colocado no leito com a cabeceira elevada. Ocorreria uma situação semelhante à drenagem liquórica lombar continua sem a desvantagem do risco, quase certo, de uma infecção.

O resultado obtido no caso $1 \mathrm{fez}$ com que continuássemos usando o método em outros pacientes mesmo sem a localização do pertuito dural. Raciocínio semelhante utilizaram Greenblatt e Wilson ${ }^{4}$ em 1973; estes autores preconizam derivações lombo-peritoniais valvuladas na terapêutica da rinorréia persistente. A possível desvantagem desta derivação valvulada seria a permanência indefinida da drenagem. Na técnica aqui proposta há uma drenagem liquórica que permanece por um prazo aproximado de duas semanas com ulterior ausência de absorção e drenagem.

A análise da casuística permite observar que houve controle da fístula liquórica em todos os pacientes em que a técnica foi utilizada. Especialmente nos casos 1,2 e 5 foi possível obter um acompanhamento relativamente prolongado, sendo o mais longo de 20 meses. Em nenhum dos pacientes houve recidiva apesar da vida normal que mantiveram após a intervenção cirúrgica. Em somente um paciente (caso 2) houve queixa de irritação radicular que motivou reintervenção para a remoção do cateter de drenagem. Este fato não é novo e tem sido relatado nas derivações lombo-peritoniais para o tratamento do hidrocéfalo.

A análise do material permite concluir pela simplicidade da técnica, com ausência de complicações expressivas, considerando a importância da patologia e do controle da fístula em todos os pacientes. Esses fatos autorizam a recomendação do seu uso para ulteriores observações.

\section{R E S U M O}

O autor descreve uma nova possibilidade cirúrgica para o tratamento das fístulas liquóricas por patologia de base do crânio. Consiste na derivação do líquido cefalorraqueano, por meio de cateter, do fundo de saco dural lombar para a musculatura paravertebral, no mesmo nível. A cura da fístula liquórica nos cinco pacientes em que foi utilizada, autoriza a recomendação do seu uso.

\section{S U M M A R Y}

A new technic for the treatment of the cranial cerebrospinal fluid fistula.

A new technic for the treatment of the cranial cerebrospinal fluid fistula is described. The technic consists in a shunt between the lumbar subarachnoid space to the paravertebral muscles. There were resolutions of the fistula in five cases in which this technic was used. 


\section{REFER E N I A S}

1. AITKEN, R.R. \& DRAKE, C.G. - Continous spinal drainage in the treatment of postoperative cerebrospinal fluid fistula. J. Neurosurg. 21:275, 1964 .

2. DICKMANN, G.H. - Craneorreas de Liquido Cefalorraquideo. López Libreros Ed., Buenos Aires, 1971.

3. FERREIRA, N.P. \& CORRÊA, J. - Derivação liquórica ventrículo-subcutânea na terapêutica cirúrgica das fístulas liquóricas pós-operatórias rebeldes. Neurobiol. (Recife) 35:97, 1972 .

4. GREENBLATT, S.H. \& WILSON, D.H. - Persistent cerebrospinal fluid rhinorrhea treated by lumboperitoneal shunt. J. Neurosurgery 38:524, 1973.

5. JANNY, P.; ROUGERIE, J. \& CHABANNES, J. - Le drainage ventriculaire controlé dans le chirurgie de la fosse cérébrale postérieure. Neurochirurgie (Paris) 10:204, 1964.

6. SUZUKI, J. \& TOKUO, W. - An apparatus for continous ventricular drainage. J. Neurosurg. 18:405, 1961.

Instituto de Neurocirurgia de Porto Alegre - Pavilhão São José - Santa Casa de Misericórdia de Porto Alegre RS - Brasil. 